\title{
A SHORT ACCOUNT OF AN EXPERIMENT IN CROSSING THE AMERICAN BISON WITH DOMESTIC CATTLE.
}

By Mossom M. Boyd, Bobcaygeon, Ontario.

RESULTS OF BREEDING DOMFSTIC COWS TO A BUFFALO BULL.

The Experiment was begun in 1894 by crossing a pure buffalo bull upon a variety of domestic cows, including purebred cows of the following breeds; Polled Angus, Hereford, West Highland, (one) Sussex, and (two) Devon; also Grade Polled Angus, Grade Galloways, and a number of the sort known as scrubs. The object in this variety was to learn which sort would yield the choicest fur. Unfortunately no produce was got from any of the 6 West Highland nor from the 2 Devons, and for the rest $I$ could not distinguish any marked difference in the length and quality of fur on the hybrids. As to the more conspicuous character of color the following table shows the result in 28 instances:

Color and Horn Characters of Progeny from Crossing a Buffalo Bull with Cows of Different Breeds.

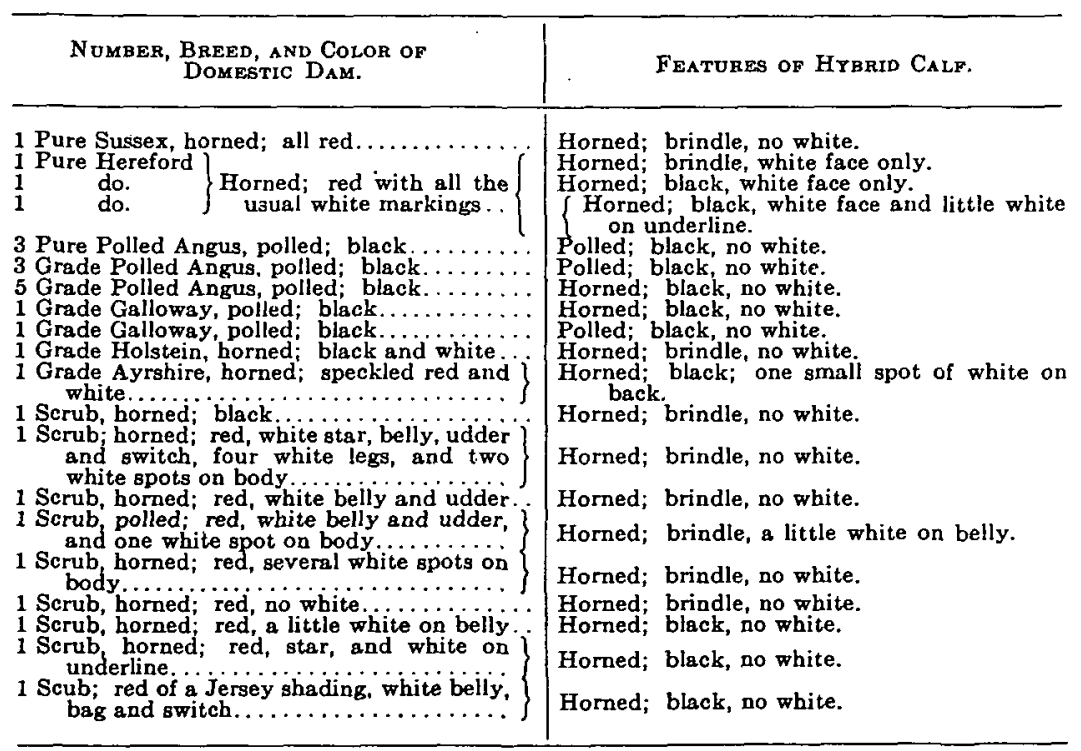

From this table it is seen that the white face of the Hereford dominated in every case, but that otherwise the whole-color of the buffalo dominated white markings in 9 cases out of 12 . The black of the hybrids is not the jet black of the Angus, but has a browuish tinge somewhat the shade of a new seal-skin jacket before it has 
faded; and all the blacks (whether from red dams or black) were pretty much of the same shade. The brindled animals varied in shade from yellow red to dark red and brown, but were all decidedly brindled.

\section{DOMINANT CHARACTERS.}

As to form, all the hybrids were so uniform, so nearly alike that they were fully as difficult to distinguish one from another as would be a bunch of Polled Angus cows. They had a good deal of the hump and depth-of-rib peculiar to the buffalo, and combined with it the width of their domestic dams. I would tentatively list the following characters as dominant or otherwise:

The whole body-color of the buffalo-usually dominant.

The white face of the Hereford-dominant.

The polled head of the Angus-dominant.

The hump of the buffalo-dominant, but somewhat modified.

The width of the hind-quarters of the beef breeds-dominant.

The width-in-front of the beef breeds-dominant.

The hair or fur in length and quality-intermediate.

The buffalo characteristic of shedding the old coat completely before the new coat comes in, so as to appear quite bare on the back, sides and hind-quarters, is dominated by the opposite character of the domestic, so that the hybrids do not become bare like the buffalo.

The voice of the buffalo-dominant.

\section{SUPERIOR MEAT-YIELDING CHARACTERS OF THE CATTELO.}

The Buffalo has 14 pairs of ribs, the domestic ox 13 . We have cxamined the carcasses of some 8 or 10 hybrids only, and of these found but one with 14 . This was the carcass of a bull calf born with an enlarged heart and which only lived for 24 hours. We show a photograph of the ribs and neural spines of this calf (No. 2 of fig. 1) on which the 14 ribs can be plainly counted. Also a photograph (No. 1 of fig. 1) of the same parts of a domestic calf of the same sex and age for the purpose of comparison. These show the greatly superior length of the neural spines in the hybrid thorax. The neural spines are the upward bony projections from the spinal column. Alongside these spines lie some of the choicest cuts in a carcass of beef. The depth of these cuts is accordingly much greater in a hybrid than in a domestic carcass.

This part of a buffalo, commonly called his hump, is not as some suppose, a mass of fat stored for the animal's support in time of starvation; but is the seat of huge muscles which largely account for the buffalo's great strength and activity; for, although clumsy in appearance, he is really a very active bovine and his head is not so large in proportion to bis body as it is made to appear by its immense covering of long hair.

Taking the depth of the thorax from the top of the neural spines to the bottom of the ribs, which depth is practically equal in the two figures, notice how the spinal column of the hybrid seems to run 
much nearer the centre. Compare the great length of the neural spines and the comparitive shortness of the ribs in the hybrid, with the short neural spines and comparatively long ribs of the domestic skeleton, and remember it is alongside of the neural spines that the meat is thick and high-priced, whereas on the lower portion of the ribs it is thin and low-priced. This would appear to be the foundation for the most valuable kind of carcass.

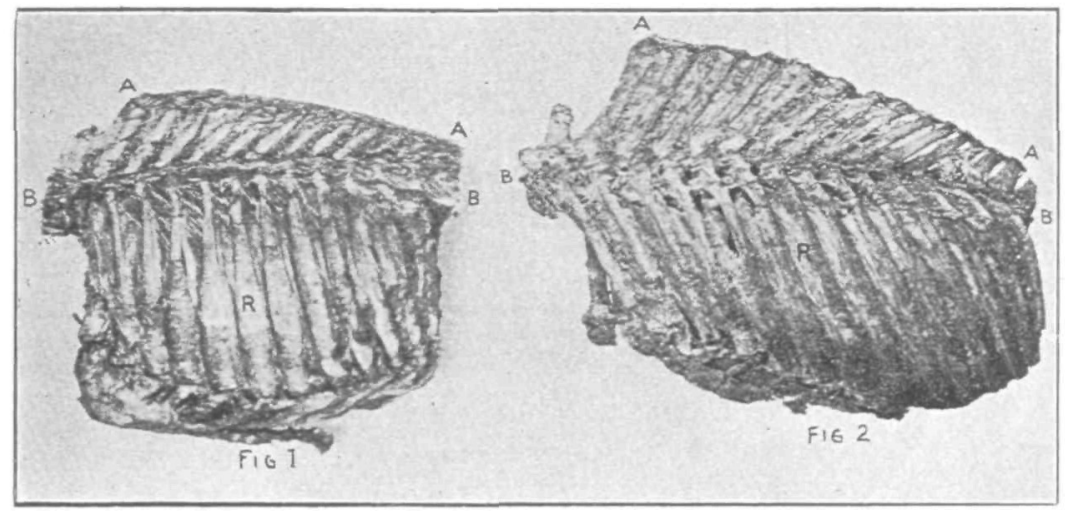

The accompanying illustration (fig. 2), showing how beef is cut and valued in Chicago, is taken from Farmers' Bulletin No. 71 of the U. S. Department of Agriculture, and is practically identical with an illustration published in the Breeders' Gazette of December 29,1897 . It should be noted that the most valuable part of the carcass is the back from the shoulder to the loin.

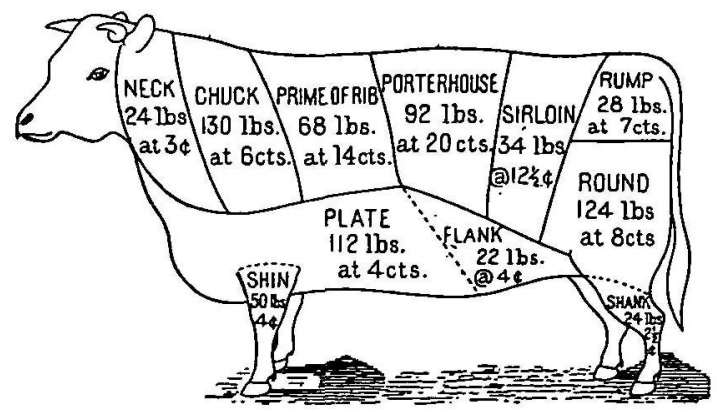

Fig. 2.-Chicago retail dealers' method of cutting up beef (prices of 1897). 


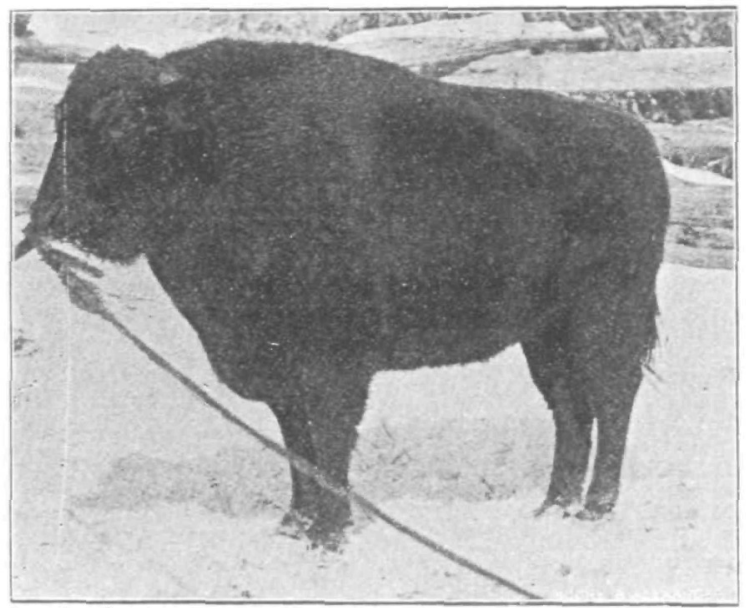

Fig. 3.-A hybrid buffalo (or cattelo) cow (from a photograph).

A comparison of figures 2 and 3 shows that the back of the hybrid is increased just where the cuts are most valuable.

Here is a radical improvement obtained in one cross; as much as, or more than," we could reasonably hope to effect in a century by the customary method of selecting.

\section{IMPRACTICABILITY OF THE CROSS.}

Unfortunately. I must now proceed to explain the impracticability of this cross, and this would be indeed a sorry task were it not for the possibility of arriving at equally good results in another way.

The buffalo bull used in 1894 as the beginning of the experiment was purchased in November, 1893 , from Mr. B. C. Winston of Monterey, California. It is the same animal mentioned on page 522, Smithsonian Report, 1887, as the calf captured alive by Mr. Winston in the Spring of 1886 when on a hunting expedition about 75 miles west of Grand Rapids, Dakota. At the time of purrhase Mr. Winston showed me 4 very fine hybrids (two yearlings and two calves) got by this bull from domestic cows; and the exhibit of these acted as an inducement to the purchase of the bull, for it was a matter of some value to have evidence of the bull's capacity. At the same time Mr. Winston complained that he had been most unfortunate in losing several of his domestic cows, as well as a pure buffalo cow. $\mathrm{He}$ attributed the loss to particles of glass sand which he thought had been swallowed along with the grass on his sea-shore pastures. This he said gave the cattle indigestion so that they bloated and died.

The writer conceived later another explanation of the deaths of Mr. Winston's domestic cows when he came to have experience in the breeding of buffalo hybrids, for it became apparent in the season 
of 1894 that the effect upon domestic cows of impregnation by the buffalo was almost without exception an abnormal secretion of the amniotic fluid; and to such an extent was this (dropsical ?) condition of the womb developed that it caused many abortions and deaths. The animals appeared to be enormously bloated; and besides the drain on the vital system, the vital organs were apparently paralysed by compression to the point of death in some cases. In other cases a rupture of the sack occurred allowing the amniotic fluid to escape; abortion followed, and if not too much exhausted the cow recovered. There was no exception to this abnormal secretion in a greater or less degree. Many of the cows which pulled through to the end and produced healthy calves were thus afflicted almost to the same extent as those which succumbed, although the calves were not at all adversely affected, but were exceptionally strong (as compared with domestic calves) from the moment of birth.

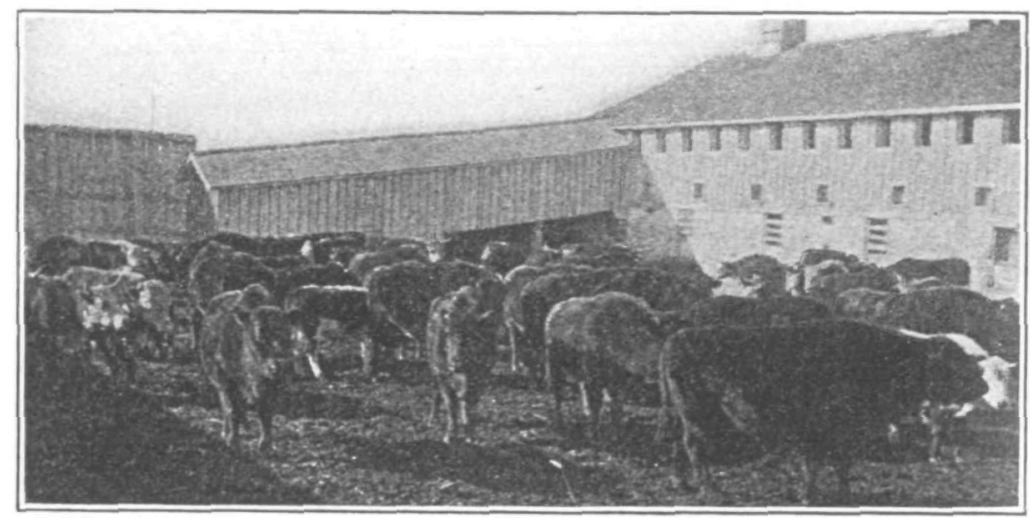

Fig. 4.-A herd of cattelo; a few domestic cattle in the rear.

As to whether the period of gestation in the bison differs in length from that of the domestic cow I do not know, but in the case of 39 successful hybrid births the time varied from 244 to 277 days, with an average of 264 , which is an ordinary period for the domestic cow, but on the whole somewhat shorter than the average. In the case of abortions, the average period between impregnation and abortion was 178 days, and varied from 114 to 244 days. As against 39 successful births we had 63 abortions, and among the latter a number of deaths. Our experience, therefore, leads us strongly to advise against any attempt to repeat this cross. We did not try it a second time, excepting that 5 cows which were successful on the first trial were impregnated again, with the object of ascertaining whether they had acquired any immunity to this serious affection. Of the 5, one died on the 204th day after impregnation, 3 aborted on the 161 st, 182nd and 243 rd day respectively, and only 1 produced 
a living calf-which she carried 262 days-with, however, less difficulty than either she herself or any other cow had experienced during the first trial.

\section{RESULTS OF BREEDING HYBRID COWS.}

Fortunately we got from our first trial a sufficient number of hybrids with which to continue experimenting. We had in all, as stated above, 39 births, of which only 6 were males; and of these 6,3 died at birth, and 1 lived only twenty-four hours. This very small proportion of males, namely $151-3$ per cent, is so much below the normal as to lead to the conclusion that it is the result of some special cause. Included among the 39 births are 5 which died at hirth, 2 which died within a week, 1 at two weeks (of scours), 1 at three weeks, 2 at one year old (from stomach and liver trouble), 1 drowned at one year old, and 2 slaughtered (for a special purpose) at two years old; so that but 25 animals including only 1 bull were raised to a breeding age. The bull proved to be barren, and at six years of age was disposed of to the Zoological Park in Toronto, where, I believe, he still is. Fifteen females produced no progeny, although kept to the following ayes and tried with both buffalo bulls and domestic bulls:

One to 3 years and 9 months; one to 4 years and 2 months; one to 5 years and 4 months; five to 6 years; three to 7 years; four to 8 years.

Nine others proved to be breeders, but only three of the nine were perfectly reliable and regular breeders, as will be seen from the following table:

Breeding record of hybrids-December 31, 1907.

\begin{tabular}{|c|c|c|c|c|c|c|c|c|c|c|c|c|c|}
\hline \multicolumn{2}{|l|}{ Hybrid Cow. } & \multicolumn{10}{|c|}{ Progeny. } & \multicolumn{2}{|c|}{$\begin{array}{l}\text { Age of dam } \\
\text { when sht } \\
\text { produced her } \\
\text { first calf. }\end{array}$} \\
\hline Parentage. & $\begin{array}{l}\text { Date of } \\
\text { Birth. }\end{array}$ & 98 & '99 & '00 & 01 & 102 & '03 & '04 & 05 & '06 & '07 & Yrs. & Mos. \\
\hline $\begin{array}{l}\text { Buffalo X Grade Angus . . } \\
\text { Buffalo X Grade Angus . } \\
\text { Buffalo X Scrub....... } \\
\text { Buffalo X Pure Hereford. } \\
\text { Buffalo X Pure Angus.... } \\
\text { Buffalo X Grade Angus... } \\
\text { Buffalo X Grade Angus... } \\
\text { Buffalo X Pure Hereford.. } \\
\text { Buffalo X Grade Holstein. }\end{array}$ & $\begin{array}{l}\text { May 3, '95 } \\
\text { Feb. 24, '95 } \\
\text { May. 27, ' } 95 \\
\text { Jan. 27, '95 } \\
\text { Jun. 5, '96 } \\
\text { May 20, '95 } \\
\text { Mar. 11, ' } 95 \\
\text { Jun. 18, '95 } \\
\text { Jan. 22, '95 }\end{array}$ & \begin{tabular}{l|}
$\mathrm{B}^{\mathbf{1}}$ \\
$\cdots$ \\
$\cdots$ \\
$\cdots$ \\
$\cdots$ \\
$\cdots$ \\
$\cdots$ \\
$\cdots$
\end{tabular} & $\begin{array}{c}\dot{\mathbf{C}}^{\mathbf{2}} \\
\mathbf{C} \\
\cdots \\
\cdots \\
\cdots \\
\cdots\end{array}$ & $\mid \begin{array}{c}\dot{\mathbf{C}} \\
\dot{\mathbf{B}} \\
\mathbf{B} \\
\mathbf{C} \\
\mathbf{B} \\
\cdots\end{array}$ & $\begin{array}{l}\cdots \\
\cdots \\
\dot{\mathrm{C}} \\
\dot{\mathrm{C}} \\
\stackrel{\mathrm{C}}{ }\end{array}$ & $\mid \begin{array}{c}\mathrm{B} \\
\cdots \\
\cdots \\
\mathrm{C} \\
\mathrm{B} \\
\dot{\mathrm{C}}\end{array}$ & $\begin{array}{c}\mathrm{B} \\
\cdots \\
\cdots \\
\mathrm{C} \\
\cdots \\
\cdots\end{array}$ & $\begin{array}{c}\dot{\mathrm{C}} \\
\cdots \\
\cdots \\
\dot{\mathrm{B}} \\
\cdots\end{array}$ & $\mid \begin{array}{c}\dot{\mathrm{C}} \\
\dot{\mathrm{C}} \\
\dot{\mathrm{B}} \\
\mathrm{C} \\
\cdots \\
\cdots\end{array}$ & $\mid \begin{array}{c}\dot{\mathrm{C}} \\
\cdots \\
\cdots \\
\dot{\mathrm{C}} \\
\mathrm{B} \\
\cdots \\
\cdots\end{array}$ & $\mid \begin{array}{c}\dot{\mathrm{C}} \\
\cdots \\
\cdots \\
\mathrm{B} \\
\mathrm{B} \\
\cdots \\
\cdots\end{array}$ & $\begin{array}{l}3 \\
4 \\
4 \\
5 \\
3 \\
4 \\
5 \\
5 \\
6\end{array}$ & $\begin{array}{r}3 \\
5 \\
2 \\
2 \\
9 \\
11 \\
2 \\
9 \\
3\end{array}$ \\
\hline Totals and average & $\ldots \ldots \ldots$ & 1 & 2 & 5 & 4 & 4 & 2 & 2 & 4 & 3 & 3 & 4 & 0 \\
\hline
\end{tabular}

From this table it will also be seen that the average age at which the hybrids produced the first calf was four years (and seven days). What may be the usual average for the pure buffalo cow I do not know. 
It will be noticed that the 30 calves of this second generation comprise 12 bulls and 18 females; that is 40 per cent, bulls, as compared with 15 1-3 per cent in the first cross between the two species. Some of these calves were sired by domestic bulls, and are consequently one-quarter buffalo; others by pure buffalo bulls, and are therefore three-quarters buffalo. The 1907 calves are the only animals having mixed buffalo, or cattelo blood, on both sides. I use the term cattelo (suggested by Mr. Jones) to designate animals of the mixed blood in all proportions, including the hybrids. The term hybrid is applied only to the result of the first cross between the two species.

Time enough has not yet elapsed in which to learn the breeding qualities of these one-quarter and three-quarters buffaloes, but indications are that the one-quarter buffalo females will be ordinarily prolific, or nearly so. Our three-quarters buffalo females have not yet been fully tested. On the other hand we have reason to believe that many of the one-quarter buffalo bulls will be barren. Out of 4 tried we have one that breeds; 3 were abandoned as barren at 36 months, 32 months and 25 months of age, respectively, possibly before they had come to maturity.

The domestic blood in our catteloes is almost altogether Polled Angus and Hereford, more largely the former. We have some that contain pure Hereford and buffalo blood only; others that are a triple mixture of pure Hereford, pure Angus, and buffalo; and others that are Angus and buffalo. The one-quarter and threequarters buffaloes are markedly different from the hybrids of the original cross; the former (one-quarter) very much resemble domestic cattle, and the latter (three-quarters) are nearly like pure buffaloes. Those which are one-quarter buffalo and three-quarters Angus have not the seal-brown tinge of hair seen in the first cross, but the almost jet black of the Angus. Those which are one-quarter Angus and three-quarters buffalo are very much like pure buffaloes, but of a darker shade and smoother build.

\section{WHERE HOPE OF SUCCESS LIES.}

By using domestic bulls, one rapidly gets away from all resemblance to the buffalo; and vice versa, by using the pure buffalo bull one soon grades up to an animal indistinguishable from the pure buffalo. Our hope lay in breeding the catteloes together; but before we could do so we had to await the arrival of a fertile cattelo bull; and our 1907 calves are the first bred in this way. They are as yet not sufficiently developed to warrant description here.

It is too soon to predict either success or failure for this experiment, and many more years must probably elapse before the question is settled. If, by weeding out the delinquents, we can arrive within a reasonable time at a thoroughly fertile herd of catteloes bearing a goodly portion of buffalo blood, we believe success will follow. 
I think it is within the mark to say that such animals as our hybrids (buffalo X Angus or Hereford) are worth from 50 per cent to 100 per cent more than domestic cattle for slaughter. They are larger, yield finer carcasses of beef, and have a very valuable pelt. The pelt of the hybrid appears to be of even more value than that of the pure buffalo, excepting when the latter is valued as a souvenir; it is of a better color, has more lustre, with hair nearly as long and not matted. While some might not prefer the fur of the first cross to that of the pure buffalo, there are very few who would not perfer the fur of the three-quarters buffalo. On account of the fatalities attending so severe a cross, it is however, out of the question to breed hybrids; but we may look to the possibility of producing a cattelo capable of giving equally good results and without risk. A.cattelo bull, which without sacrificing other desirable characters, would put the valuable pelt described above on domestic stock in one or two crosses, would be very valuable. It remains to be seen whether such a bull can be produced. There remains also the possibility, by breeding catteloes to catteloes, of forming one or more valuable races of cattle combining in a greater or less degree the more valuable characteristics of each species; the greater degree becoming gradually predominant as selection is persevered in during succeeding generations.

\title{
REPORT OF COMMITTEE ON BREEDING HORSE HYBRIDS.
}

\author{
Prof. F. R. Marshall, Columbus, Ohio, Chairman, \\ Dr. H. J. W Aters, Columbia, Mo., F. B. Momford, Columbia, Mo., \\ Dr. A. D. Melvin, Washington, D. C., C. M. Evans, College Station, Tex., \\ J. L. JoNes, Columbia, Tenn.
}

OвJEcTs: To investigate and report on the possibilities, methods and technique of making improved hybrids by crossing the horse, ass, zebra and other related species with a view to producing a fertile horse hybrid draft animal; and to encourage the production in large numbers of a race of draft animals, long-lived, resistant to disease, sound in feet and limbs, strong and active, requiring a small amount of food, intelligent, teachable, agreeable in disposition, and comely in appearance.

(Report submitted by the Chairman.)

Inasmuch as another committee of this association is studying the general subject of animal hybridization, it has appeared wisest for this committee to confine its work to the fertility of the mule.

No authenticated case is yet on record where a female mule has conceived or produced young though in innumerable cases there has been full opportunity for them to do so. "Undoubtedly also the male mule would have produced offspring had he the power.

Strange as it may seem there is no record to show that any qualified investigator has ever attempted any kind of an examination of the ovaries or the testicles of mules with a view to determining the cause of sterility. 